\title{
Epicardial fat tissue in patients with diabetes mellitus: a systematic review and meta-analysis
}

\author{
Yingrui Li ${ }^{\dagger}$, Bin Liu ${ }^{\dagger}$, Yu Li, Xiaodong Jing, Songbai Deng, Yulin Yan and Qiang She*
}

\begin{abstract}
Background: Epicardial fat tissue (EFT) is the visceral fat distributed along the coronary arteries between the pericardium and the myocardium. Increases in EFT are closely related to the occurrence of diabetes mellitus (DM) and cardiovascular disease. To further understand the link between EFT and DM, we conducted a meta-analysis of the relevant literature.

Methods: We systematically searched electronic databases for studies on EFT performed in DM patients and published up to 30 September 2018. We included data on EFT in a DM patient group and a non-DM control group. We then assessed the effect of DM on EFT by meta-analysis and trial sequential analysis (TSA). All statistical analyses were performed using Stata 12.0 and TSA software.

Results: A total of 13 studies ( $n=1102$ patients) were included in the final analysis. Compared with the control group, DM patients had significantly higher EFT (SMD: 1.23; 95\% Cl 0.98, 1.48; $\mathrm{P}=0.000 ;$ TSA-adjusted 95\% Cl 0.91, 2.13; $P<0.0001)$. The TSA indicated that the available samples were sufficient and confirmed that firm evidence was reached. According to the regression analysis and subgroup analyses, DM typing, EFT ultrasound measurements, total cholesterol (TC) and triglyceride (TG) levels were confounding factors that significantly affected our results.
\end{abstract}

Conclusions: Our meta-analysis suggests that the amount of EFT is significantly higher in DM patients than in nonDM patients.

Keywords: Epicardial fat tissue, Diabetes mellitus, Meta-analysis

\section{Background}

Diabetes mellitus (DM) is one of the most common metabolic diseases worldwide and is characterized as a metabolic disorder of carbohydrates, proteins and lipids [1]. In recent years, the incidence of DM has gradually increased, becoming a serious public health threat $[2,3]$. DM can be divided into type 1 diabetes mellitus (T1DM), type 2 diabetes mellitus (T2DM), gestational diabetes mellitus (GDM) and other types of diabetes. Abnormally accumulated visceral fat is a risk factor for insulin resistance, which can reduce insulin sensitivity, increase the

\footnotetext{
*Correspondence: qshe98@hotmail.com

${ }^{\dagger}$ Yingrui Li and Bin Liu contributed equally to this work

Department of Cardiology, The Second Affiliated Hospital of Chongqing

Medical University, Chongqing 400016, China
}

expression and secretion of proinflammatory cytokines in adipose tissue and promote the development of DM and cardiovascular diseases [4-7].

Epicardial fat tissue (EFT) is a visceral adipose tissue that surrounds the myocardium and pericardium. It is one of the visceral fat stores in the body. Previous studies have suggested that measurements of EFT are a substitute for visceral fat $[8,9]$ EFT can secrete inflammatory factors, such as TNF-alpha, IL-6, adipocytokines, and leptin, via paracrine or endocrine activities $[9,10]$ to locally regulate the myocardium and coronary artery function and regulate lipid and energy homeostasis in vivo. EFT has the ability to release and uptake free fatty acids and to affect low glucose utilization, which plays an important role in metabolic syndrome and coronary artery disease [11-16]. EFT can be measured by echocardiography, 
cardiac magnetic resonance imaging, and computed tomography (CT) [17]. Recent studies have confirmed that EFT is associated with obesity, fasting blood glucose levels, insulin resistance, and adiponectin in patients with T2DM, and an increase in EFT was observed in patients with T1DM and T2DM [18-22].

In the past few years, several studies have reported that EFT is abnormally increased in DM patients. However, small sample sizes and potential confounders (such as differences in EFT measurements and DM typing) can affect the strength of previous evidence. Therefore, in this study, we conducted a meta-analysis to evaluate the effect of DM on EFT volume to provide a comprehensive overview of this issue.

\section{Methods}

We conducted this meta-analysis in strict accordance with the PRISMA reporting specifications.

\section{Search strategy}

According to the PRISMA guidelines [23], we developed a detailed search strategy. We systematically searched online databases (PubMed, EMBASE, Cochrane Library, and Web of Science) up to 30 September 2018 and included all possible combinations of the following search terms: (diabetes mellitus OR Diabetes mellitus, type 2 OR diabetes mellitus, type 1) AND (epicardial fat tissue OR epicardial adipose tissue OR subepicardial adipose tissue OR subepicardial fat tissue). This study was limited to human studies published in English studies.

\section{Inclusion criteria}

Identified studies were enrolled based on the following inclusion criteria: (1) DM patients were an experimental group and non-DM subjects were a control group; (2) quantitative measurement of EFT volume or thickness by echocardiography, cardiac magnetic resonance imaging or CT; (3) study of differences in EFT between DM patients and non-DM subjects; (4) the study reported a mean, standard deviation (SD), and sample size for DM patients and non-DM subjects; and (5) observational studies.

\section{Exclusion criteria}

During the literature screening process, studies containing the following items were excluded: (1) experimental animal studies, reviews, or non-English literature; (2) the study did not provide sufficient information about the dataset (mean, SD and sample sizes).

\section{Data extraction and quality assessment}

Two reviewers (Yingrui $\mathrm{Li}$ and Bin Liu) independently extracted data and assessed the quality of each study.
If there was disagreement on a specific study, the two reviewers negotiated to reach a consensus. The data extracted from each study included the sample size and EFT of the experimental and control groups. Then, the Newcastle Ottawa scale (NOS) was used to assess the quality of the study. The scoring system consisted of three parts (population selection, comparability between groups, and exposure factors), and the results ranged from 0 to 9 , with higher scores representing better methodology quality (Table 1).

\section{Data analysis}

All statistical analyses were performed using Stata 12.0 using a fixed effect model or a random effects model to calculate the pooled standard mean difference (SMD) or weighted mean difference (WMD) for a 95\% CI. All reported $P$ values are two-sided with a significance level set at $P<0.05$. The heterogeneity of each study was assessed by calculating the $\chi^{2}$ and $\mathrm{I}^{2}$ statistics. If $P<0.1$ and $\mathrm{I}^{2}>30 \%$, a random effects model was applied; otherwise, a fixed effects model was applied [24]. Considering the potential impact of DM confounding factors on the results of the study, we performed a subgroup analysis of DM typing and EFT measurements. At the same time, we applied a sensitivity analysis to examine the impact of individual studies on the total merged effects to assess the reliability of the conclusions. We analyzed the symmetry of a funnel plot to evaluate possible small sample effects, and we used Begg's test as well as Egger's test to evaluate publication bias in the included studies. Statistical significance was considered at $\mathrm{P}<0.10$ [25]. If publication bias was detected, the Duval and Tweedie's trim and fill method was applied using the random effects model to evaluate the adjusted effect scale [26]. Taking into account the differences between the studies, all our analyses used a random effects model.

Meta-regression is often used to explore the source and size of heterogeneity in a study and to further explain the impact of heterogeneity in a meta-analysis. We hypothesized that the included studies may have shown differences in cardiovascular disease risk factors (BMI, dyslipidemia, waist hip rate) in DM patients. To assess the possible effects of these variables on the different outcomes observed in the meta-analysis, we established a regression model with the EFT value as the dependent variable ( $y)$ and the abovementioned covariate as the independent variable $(\mathrm{x})$.

In a conventional meta-analysis, repeated significance testing of cumulative data increases the overall risk of type I error; however, TSA can reduce the risk of type I error and estimate the required information size (RIS) needed to achieve a preset power level, draw benefit 
Table 1 Characteristics of included studies

\begin{tabular}{|c|c|c|c|c|c|c|c|c|c|}
\hline Study & Country & Arms & Diabetes type & $\mathrm{N}$ & Age (year) & BMI $\left(\mathrm{Kg} / \mathrm{m}^{2}\right)$ & EFT & Measurement tool & NOS Score \\
\hline \multirow[t]{2}{*}{ Chen et al. [27] } & China & Diabetes & $\|$ & 167 & $43.7 \pm 10.9$ & $22.6 \pm 2.1$ & $4.0 \pm 1.5 \mathrm{~mm}$ & $\begin{array}{l}\text { Echocardiography } \\
\text { (end-diastole par- } \\
\text { asternal long axis) }\end{array}$ & 7 \\
\hline & & Non-diabetes & & 82 & $42.4 \pm 10.2$ & $22.0 \pm 2.1$ & $2.0 \pm 1.5 \mathrm{~mm}$ & & \\
\hline \multirow[t]{2}{*}{ Yazici et al. [29] } & Turkey & Diabetes & 1 & 36 & $30.8 \pm 7.7$ & $24.7 \pm 3.8$ & $3.3 \pm 1.1 \mathrm{~mm}$ & $\begin{array}{l}\text { Echocardiography } \\
\text { (end-diastole } \\
\text { parasternal average } \\
\text { axis) }\end{array}$ & 7 \\
\hline & & Non-diabetes & & 43 & $29.9 \pm 4.9$ & $24.6 \pm 3.0$ & $2.3 \pm 0.3 \mathrm{~mm}$ & & \\
\hline \multirow[t]{2}{*}{ lacobellis et al. [20] } & American & Diabetes & 1 & 15 & $52.8 \pm 12.0$ & $27.8 \pm 5.2$ & $7.2 \pm 2.1 \mathrm{~mm}$ & $\begin{array}{l}\text { Echocardiography } \\
\text { (end-systole } \\
\text { parasternal average } \\
\text { axis) }\end{array}$ & 7 \\
\hline & & Non-diabetes & & 15 & $53.0 \pm 9.0$ & $27.4 \pm 4.1$ & $4.9 \pm 2.5 \mathrm{~mm}$ & & \\
\hline \multirow[t]{2}{*}{ Cetin et al. [21] } & Turkey & Diabetes & $\|$ & 139 & $54.3 \pm 9.2$ & $27.6 \pm 3.1$ & $6.0 \pm 1.5 \mathrm{~mm}$ & $\begin{array}{l}\text { Echocardiography } \\
\text { (end-diastole } \\
\text { parasternal average } \\
\text { axis) }\end{array}$ & 7 \\
\hline & & Non-diabetes & & 40 & $52.1 \pm 7.3$ & $29.1 \pm 4.2$ & $4.4 \pm 1.0 \mathrm{~mm}$ & & \\
\hline \multirow[t]{2}{*}{ Seker et al. [33] } & Turkey & Diabetes & $\|$ & 186 & $62.5 \pm 9.6$ & $28.6 \pm 4.4$ & $6.5 \pm 0.7 \mathrm{~mm}$ & $\begin{array}{l}\text { Echocardiography } \\
\text { (End-systole } \\
\text { parasternal average } \\
\text { axis) }\end{array}$ & 7 \\
\hline & & Non-diabetes & & 268 & $61.2 \pm 10.9$ & $27.6 \pm 4.2$ & $5.3 \pm 1.0 \mathrm{~mm}$ & & \\
\hline \multirow[t]{2}{*}{ Aslan et al. [37] } & Turkey & Diabetes & 1 & 76 & $30.6 \pm 10.3$ & $23.3 \pm 2.7$ & $3.6 \pm 0.5 \mathrm{~mm}$ & $\begin{array}{l}\text { Echocardiography } \\
\text { (end-diastole } \\
\text { parasternal average } \\
\text { axis) }\end{array}$ & 7 \\
\hline & & Non-diabetes & & 36 & $32.4 \pm 8.5$ & $24.2 \pm 2.7$ & $3.0 \pm 0.5 \mathrm{~mm}$ & & \\
\hline \multirow[t]{2}{*}{ Wang et al. [32] } & China & Diabetes & $\|$ & 68 & $59.5 \pm 9.9$ & $26.9 \pm 5.9$ & $5.0 \pm 1.2 \mathrm{~mm}$ & $\begin{array}{l}\text { Echocardiography } \\
\text { (end-diastole par- } \\
\text { asternal long axis) }\end{array}$ & 7 \\
\hline & & Non-diabetes & & 32 & $58.1 \pm 9.2$ & $23.7 \pm 5.5$ & $3.1 \pm 0.8 \mathrm{~mm}$ & & \\
\hline \multirow[t]{2}{*}{ Vasques et al. [30] } & Brazil & Diabetes & $\|$ & 31 & $45.0 \pm 6.0$ & $36.0 \pm 4.7$ & $1.0 \pm 0.3 \mathrm{~mm}$ & $\begin{array}{l}\text { Echocardiography } \\
\text { (end-systole } \\
\text { parasternal average } \\
\text { axis) }\end{array}$ & 7 \\
\hline & & Non-diabetes & & 37 & $36.0 \pm 11.0$ & $27.9 \pm 7.4$ & $0.7 \pm 0.2 \mathrm{~mm}$ & & \\
\hline \multirow[t]{2}{*}{ Wang et al. [34] } & China & Diabetes & $\|$ & 49 & $56.8 \pm 9.5$ & $27.2 \pm 3.6$ & $166.1 \pm 60.6 \mathrm{~cm}^{3}$ & $\mathrm{CT}$ & 8 \\
\hline & & Non-diabetes & & 78 & $54.1 \pm 6.5$ & $25.4 \pm 3.4$ & $123.4 \pm 41.8 \mathrm{~cm}^{3}$ & & \\
\hline \multirow[t]{2}{*}{ Keles et al. [35] } & Turkey & Diabetes & 1 & 45 & $34 \pm 7.7$ & $24.1 \pm 3.4$ & $7.0 \pm 2.3 \mathrm{~mm}$ & $\begin{array}{l}\text { Echocardiography } \\
\text { (end-diastole par- } \\
\text { asternal long axis) }\end{array}$ & 6 \\
\hline & & Non-diabetes & & 35 & $32 \pm 7.3$ & $26.7 \pm 6.5$ & $6.0 \pm 1.5 \mathrm{~mm}$ & & \\
\hline \multirow[t]{2}{*}{ Akbas et al. [36] } & Turkey & Diabetes & $\|$ & 156 & $53.62 \pm 9.33$ & $31.21 \pm 5.87$ & $4.7 \pm 1.6 \mathrm{~mm}$ & $\begin{array}{l}\text { Echocardiography } \\
\text { (end-diastole } \\
\text { parasternal average } \\
\text { axis) }\end{array}$ & 7 \\
\hline & & Non-diabetes & & 50 & $51.06 \pm 8.74$ & $32.86 \pm 7.52$ & $3.9 \pm 1.6 \mathrm{~mm}$ & & \\
\hline \multirow[t]{2}{*}{ Akyürek et al. [31] } & Turkey & Diabetes & $\|$ & 90 & $57.7 \pm 11.4$ & $28.9 \pm 4.4$ & $172.8 \pm 64.9 \mathrm{~cm}^{3}$ & $\mathrm{CT}$ & 7 \\
\hline & & Non-diabetes & & 62 & $55.6 \pm 10.7$ & $26.5 \pm 2.9$ & $68.9 \pm 37.7 \mathrm{~cm}^{3}$ & & \\
\hline \multirow[t]{2}{*}{ Philouze et al. [28] } & American & Diabetes & $\|$ & 44 & $56.0 \pm 6.0$ & $26.9 \pm 3.2$ & $6.4 \pm 1.7 \mathrm{~mm}$ & $\begin{array}{l}\text { Echocardiography } \\
\text { (end-systole } \\
\text { parasternal average } \\
\text { axis) }\end{array}$ & 6 \\
\hline & & Non-diabetes & & 35 & $52.0 \pm 7.0$ & $24.2 \pm 3.6$ & $3.3 \pm 1.1 \mathrm{~mm}$ & & \\
\hline
\end{tabular}


boundaries and harm boundaries, and calculate futility. An RIS used with boundaries can infer whether further studies are needed [28]. We conducted the TSA with a $5 \%$ risk of a type I error and a power of $80 \%$ as well as an a-spending adjusted $95 \% \mathrm{CI}$ for repetitive significance testing.

\section{Availability of data and materials}

All the data were extracted from public sources.

\section{Results}

\section{Description of the studies}

Our search strategy yielded a total of 969 studies. After excluding repeated studies, there were 726 studies, of which 511 were decided to be irrelevant to our review topic after confirming the title or abstract. A further 196 studies lacked sufficient data, 5 were studies of animals, and 1 was excluded because it was not published in English. Therefore, our final analysis included 13 studies (1102 patients with DM and 813 healthy control subjects) that measured EFT in a DM group and a control group [20, 21, 27-37] (Fig. 1).

The main features of the studies are shown in Table 1. The number of patients in each study ranged from 15 to 186. EFT thickness was measured by echocardiography in 11 studies [20, 21, 27-30, 32, 33, 35-37], and the volume of EFT was measured by CT in 2 studies [31-34]. We assessed the characteristics and quality of these studies by NOS score.

\section{DM group versus control group}

EFT was reported in all studies and was significantly higher in 1102 patients with DM than in 813 control subjects (SMD: 1.23 ; 95\% CI 0.98, 1.48; $P=0.000$, Fig. 2a). There was significant heterogeneity among the studies $\left(\mathrm{I}^{2}=80.8 \%, P=0.000\right)$. The TSA showed that the cumulative z-curve crossed the boundary for futility (TSAadjusted 95\% CI 0.91, 2.13; $P<0.0001$, Fig. 2b).

Publication bias in the included studies may have affected the results of our meta-analysis. Therefore, we used a funnel plot, Begg's test and Egger's test to assess potential publication bias in the included studies. Less publication bias was observed in our evaluation of the funnel plots for the DM and control groups (Fig. 3a), and this finding was confirmed by Egger's test $(P=0.869)$ and Begg's test $(P=0.855$, Fig. $3 \mathrm{~b})$.

We performed a sensitivity analysis by deleting individual studies one by one and performing an additional meta-analysis with each study removed. We evaluated the effect of each deletion on the pooled SMD. Based on the sensitivity analysis results, we observed that none of the studies affected the overall effect, indicating that our meta-analysis is statistically stable.
To eliminate the impact of confounding factors on the results of this study, we conducted two subgroup analyses. We divided the included studies into a T1DM group and a T2DM group according to the difference in DM typing and divided the included studies into a CT measurement group, an ultrasonic parasternal average axis measurement of end systolic EFT thickness group, an ultrasonic parasternal average axis measurement of end diastolic EFT thickness group and an ultrasonic parasternal long axis measurement of end diastolic EFT thickness group according to the difference in EFT measurement. The subgroup analysis indicated there was heterogeneity in the T1DM patients $(\mathrm{n}=4)$ (SMD: $0.97 ; 95 \%$ CI 0.60 , $1.35 ; P=0.000)\left(\mathrm{I}^{2}=54.1 \%, \mathrm{P}=0.088\right.$, Fig. $\left.4 \mathrm{a}\right)$, and ultrasonic parasternal average axis measurement of end systolic EFT thickness $(\mathrm{n}=4)$ (SMD: $1.47 \mathrm{~mm}$; 95\% CI 1.08, 1.85; $P=0.000)\left(\mathrm{I}^{2}=61.1\right) \%, \mathrm{P}=0.053$, Fig. 4b) showed a significant decrease. Moreover, EFT was higher in the DM patients in each subgroup than in the non-DM patients, and the total effect was statistically significant.

To evaluate other factors that may have affected the results, we conducted a regression analysis of the included studies. Our regression analysis showed that TC levels significantly affected EFT, suggesting that TC is the source of heterogeneity $\left(P=0.011, \mathrm{\tau}^{2}=0.0665\right.$, Adj R-squared $=67.31 \%, \mathrm{I}^{2}$ res $=55.97 \%$, Fig. $5 \mathrm{a}$ ). Based on regression models studied in DM patients and control subjects, we found that TG $\left(P=0.099, \mathrm{\tau}^{2}=0.1771\right.$, Adj R-squared $=22.80 \%, \mathrm{I}^{2}$ res $=79.58 \%$, Fig. $5 \mathrm{~b}$ ) was a confounding factor that significantly affected EFT. Other risk factors, including BMI $\left(\mathrm{P}=0.732, \mathrm{\tau}^{2}=0.1999\right.$, Adj R-squared $=-10.57 \%, \quad$ I-squared res $=81.70 \%$ ), low Density Lipoprotein (LDL, $\mathrm{P}=0.120, \mathrm{~T}^{2}=0.1886$, Adj $\quad$ R-squared $=17.75 \%, \quad$ I-squared res $=81.33 \%$ ), high density lipoprotein (HDL, $\mathrm{P}=0.145, \mathrm{\tau}^{2}=0.1955$, Adj R-squared $=14.75 \%$, I-squared res $=81.40 \%$ ) and systolic blood pressure $\left(\mathrm{P}=0.963, \mathrm{~T}^{2}=0.2362\right.$, Adj R-squared $=-17.10 \%$, I-squared res $=85.34 \%$ ), did not affect the results.

\section{Discussion}

This meta-analysis included 13 studies that contained 1102 patients with DM and 813 healthy subjects. Our analysis confirmed that DM is associated with an increase in EFT. Furthermore, our TSA results indicated that the available samples were sufficient and confirmed that firm evidence was reached; the sensitivity analysis further confirmed these findings. Regression analysis indicated that TC and TG levels significantly affected our results, and a subgroup analysis suggested that there were more abnormal EFTs in DM patients with different DM types and EFT measurements than in non-DM patients. 


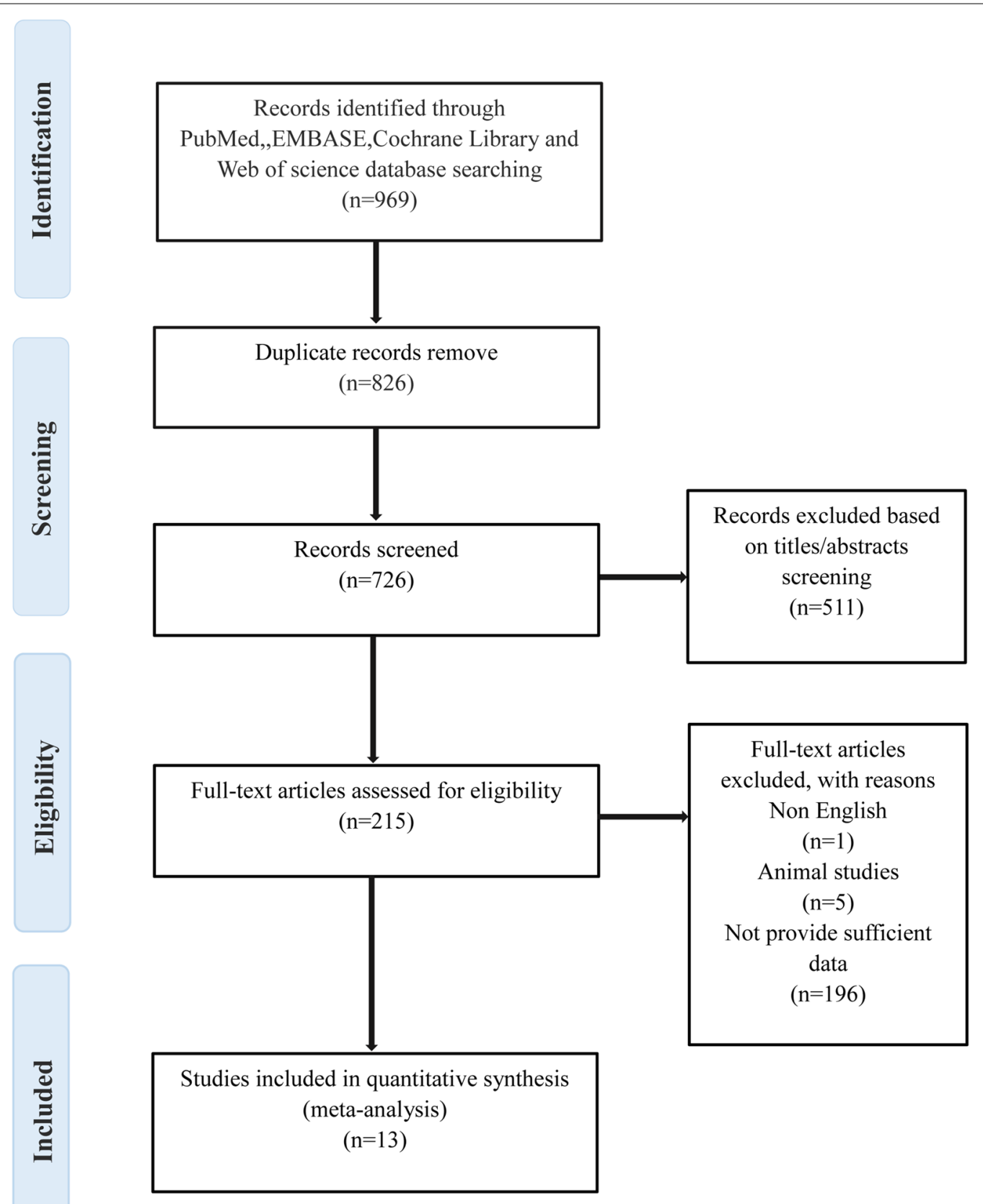

Fig. 1 Flowchart of the study selection process used to identify studies to be included in the meta-analysis

In recent years, research on the relationship between EFT and DM has gradually increased, but the reasons for the increase in EFT observed in DM patients has not been studied. Possible causes include decreased physical activity and an increased food supply, which lead to adipose tissue deposition in T2DM patients [38]. Additionally, genes associated with lipid metabolism have been shown to be missing, dislocated and mutated in DM patients [39]. Finally, T2DM patients regulate the distribution of sex steroids in body fat tissue (such as androgen) abnormally [40]. Previous studies have shown that EFT is closely related to insulin levels in serum in addition to Resistin mRNA levels and may be involved in the formation of insulin resistance. A significant increase in EFT has also been observed in chronic systemic inflammation, such as obesity and hyperlipidemia. It has been 

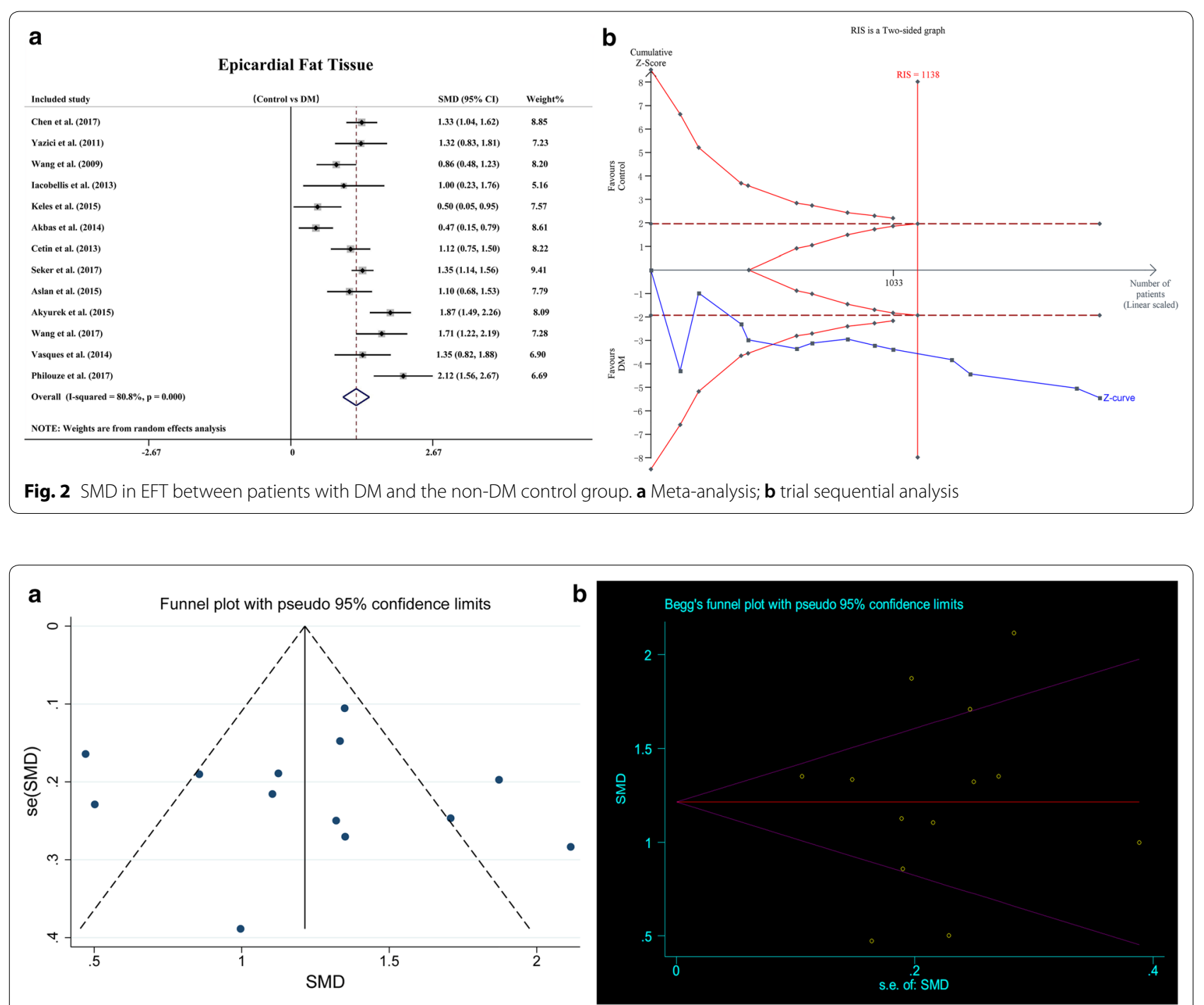

Fig. 3 Evaluation of publication bias by funnel plot and Begg's test. a Visual evaluation of the funnel plot on enrolled DM patients and the non-DM control group; b Begg's test to assess publication bias in the included studies

suggested that it is also involved in abnormal lipid metabolism in the body [41, 42].

To better understand the relationship between EFT and DM, a meta-analysis was conducted to explore the amounts of EFT in DM patients and non-DM patients. The results showed that the volume of EFT was significantly higher in DM patients with significant heterogeneity. To explore the source of heterogeneity, we conducted a subgroup analyses of different DM typing and EFT measurement methods. The heterogeneity in T1DM and the subgroup measuring EFT thickness during the systolic period decreased significantly, suggesting that different DM typing and different EFT measurement methods may be potential sources of heterogeneity.
T1DM and T2DM have very different pathogenesis and pathological processes, and EFT plays a specific role in both types of DM. Under pathological conditions, EFT can secrete a variety of bioactive adipokines and proinflammatory factors, such as TNF-alpha, IL-6, resistin, visfatin, omentin, and leptin [43-47]. Previous studies have suggested that abnormal increases in visceral fat may play a major role in the development of insulin resistance and may therefore further promote DM [48, 49]. In a study by Galletti et al. leptin inhibited insulin synthesis and secretion and increased insulin sensitivity [50]. It has also been suggested that changes in leptin secretion or sensitivity may be related to the pathogenesis of T1DM, although these findings remain controversial 

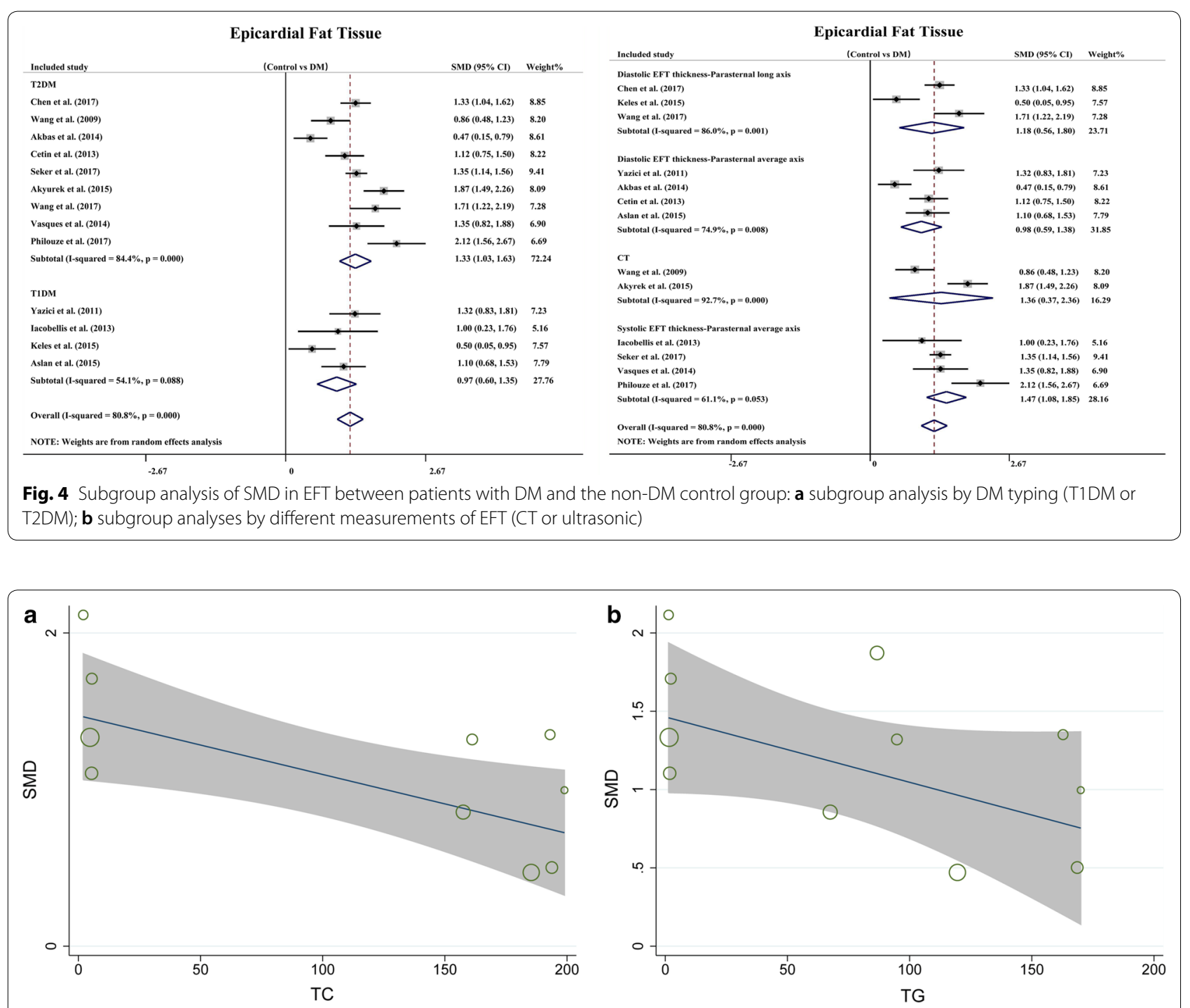

Fig. 5 Meta-regression analyses of SMD in EFT between patients with DM and the non-DM control group: $\mathbf{a}$ effect of TC on EFT; $\mathbf{b}$ effect of TG on EFT

$[50,51]$. The results of our subgroup analysis suggest that EFT is increased in both T1DM and T2DM, indicating that in the diagnosis and treatment of DM, EFT could be used as a new research target to promote the study of $\mathrm{DM}$ and provide new ideas for the clinical treatment of T1DM and T2DM.

EFT can be detected by ultrasound, CT and CMR, and EFT thickness measured by ultrasound has recently become a simple practical tool for cardiovascular risk stratification [9]. Previous studies have suggested that magnetic resonance imaging is the gold standard for estimating systemic adipose tissue [52, 53]. CMR and CT are not limited by the position and direction of the imaging plane, and it is therefore more accurate to evaluate the absolute amount of EFT compared with the ultrasound, which uses a single point measurement of EFT to assess the absolute amount of EFT. However, in the study by lacobellis et al. EFT assessment of the right ventricular free wall by echocardiography showed an excellent correlation with the EFT measurements obtained by CMR [8]. The results of our subgroup analysis showed that the volume of EFT was higher in DM patients than in non-DM patients regardless of the method of EFT measurement, suggesting that there was no significant difference among ultrasound, $\mathrm{CT}$ and CMR in the measurement of abnormal EFT increases in DM patients in clinical practice.

Epicardial adipose tissue is an extremely active adipose tissue with unique biological molecular and anatomical 
characteristics. It is not only a passive lipid storage unit but also an active participant in lipid and energy homeostasis in the myocardium. One of the biggest differences between EFT and other visceral fat is its greater ability to release and synthesize free fatty acids (FFA) $[12,54]$. Under physiological conditions, EFT exerts a cardioprotective effect through its anti-atherosclerosis/anti-inflammatory properties as well as its high FFA release and uptake rates [55]. However, abnormally increased EFT can secrete a variety of bioactive substances and excessive fatty acids, which can lead to systemic inflammation, insulin resistance, abnormal blood lipid indexes, such as TC and TG, and ultimately lead to DM, metabolic syndrome and atherosclerosis [56, 57]. Therefore, a metaregression analysis was performed to evaluate other factors (BMI, LDL, HDL, TC, TG, and systolic blood pressure) that might have had an impact on the results. The results suggested that TC and TG affected the results of this study, while other risk factors did not.

Our study indicates that compared with non-DM patients, in DM patients, the amount of EFT is significantly increased, and this has considerable clinical significance for providing new ideas for the diagnosis and treatment of DM. In a study by Kang et al. 321 CAD patients who received high-dose statins were retrospectively studied, and the results showed that EFT thickness during the systolic period was an independent predictor of new DM in patients with coronary heart disease treated with high-intensity statins [58]. At the same time, Chun et al. found that there was a significant correlation between left ventricular EFT thickness and the prevalence of diabetes in Korean men [59]. In the studies by Bouchi et al. and Sato et al., the SGLT-2 inhibitors Dapagliflozin and Luseogliflozin both improved systemic inflammation and were used for EFT, thereby reducing the EFT volume of DM patients and thus reducing the risk of cardiovascular disease [60, 61]. However, the clinical efficacy of these new therapies has not yet been confirmed, and further studies are needed [62]. Previous research results are consistent with our meta-analysis results, but previous studies did not consider the impact of other confounding factors on the results. Our results suggest that even among different types of DM or different EFT measurement techniques, patients with DM always have an abnormal increase in EFT compared with patients without DM, suggesting that the abnormal increase of EFT can be used as an independent predictor of new DM and a new target for DM drug therapy.

\section{Limitations}

We should consider some potential limitations of this study. First, five studies included [20, 28-30, 35] were small sample size. Second, there are limited studies in some subgroup analysis, and more studies are needed to support these results. Finally, it is important to assess heterogeneity among studies, and although it may not be possible to identify all possible sources of heterogeneity, the stability of our outcomes was confirmed after adjusting for potential publication bias.

\section{Future directions}

Our study indicates that DM patients have more EFT than non-DM patients, and this provides new ideas for the diagnosis and treatment of DM in the future and research into DM performed in the future. EFT is closely related to the occurrence of CHD $[63,64]$. The difference in EFT between DM patients and non-DM patients may have an important relationship with the incidence of cardiovascular diseases, but whether EFT can be used to assess the risk of cardiovascular diseases in DM patients at an early stage needs to be confirmed by further studies.

\section{Conclusions}

In general, our meta-analysis suggests that the amount of EFT is higher in DM patients than in non-DM patients regardless of T1DM or T2DM status or the EFT measurement method used. This suggests that an abnormal increase in EFT can be used as an independent predictor of new DM and a new target for DM drug therapy.

\section{Abbreviations}

EFT: epicardial adipose tissue; DM: diabetes mellitus; T1DM: type 1 diabetes mellitus; T2DM: type 2 diabetes mellitus; TSA: trial sequential analysis; TC: total cholesterol; TG: triglycerides; GDM: gestational diabetes mellitus; $C T$ : computed tomography; SD: standard deviation; NOS: Newcastle Ottawa Scale; SMD: standard mean difference; WMD: weighted mean difference; RIS: required information size.

\section{Authors' contributions}

Study design: YRL, BL; Data collection and analysis: YRL, BL, YL; Article drafting: YRL, XDJ, SBD, YLY, SQ. All authors read and approved the final manuscript.

\author{
Acknowledgements \\ Not applicable. \\ Competing interests \\ Availability of data and materials \\ responding author upon reasonable request. \\ Consent for publication \\ Not applicable. \\ Ethics approval and consent to participate \\ Not applicable. \\ Funding \\ Not applicable.
}

The authors declare that they have no competing interests.

The data that support the findings of this study are available from the cor- 


\section{Publisher's Note}

Springer Nature remains neutral with regard to jurisdictional claims in published maps and institutional affiliations.

Received: 28 October 2018 Accepted: 3 January 2019

Published online: 10 January 2019

\section{References}

1. Levesque C. Medical management of type 2 diabetes. J Nurse Pract. 2011;7(6):492-501.

2. Chen L, Magliano DJ, Zimmet PZ. The worldwide epidemiology of type 2 diabetes mellitus-present and future perspectives. Nat Rev Endocrinol. 2011;8(4):228-36.

3. Da Rocha Fernandes J, Ogurtsova K, Linnenkamp U, Guariguata L, Seuring T, Zhang P, et al. IDF Diabetes Atlas estimates of 2014 global health expenditures on diabetes. Diabetes Res Clin Pract. 2016;117:48-54.

4. Mahabadi Amir A, Massaro Joseph M, Rosito Guido A, Levy Daniel, Murabito Joanne M, Wolf Philip A, et al. Association of pericardial fat, intrathoracic fat, and visceral abdominal fat with cardiovascular disease burden: the Framingham Heart Study. Eur Heart J. 2009;30:850-6.

5. Yun CH, Lin TY, Wu YJ, Liu CC, Kuo JY, Yeh H, et al. Pericardial and thoracic peri-aortic adipose tissues contribute to systemic inflammation and calcified coronary atherosclerosis independent of body fat composition, anthropometric measures and traditional cardiovascular risks. Eur J Radiol. 2012;81:749-56.

6. Nolan CJ, Damm P, Prentki M. Type 2 diabetes across generations: from pathophysiology to prevention and management. Lancet. 2011;378:169-81.

7. Lehman SJ, Massaro JM, Schlett CL, O'Donnell CJ, Hoffmann U, Fox CS. Peri-aortic fat, cardiovascular disease risk factors, and aortic calcification: the Framingham Heart Study. Atherosclerosis. 2010;210(2):656-61.

8. lacobellis G, Assael F, Ribaudo MC, Zappaterreno A, Alessi G, Di Mario U, et al. Epicardial fat from echocardiography: a new method for visceral adipose tissue prediction. Obes Res. 2003;11:304-10.

9. lacobellis G, Corradi D, Sharma AM. Epicardial adipose tissue: anatomic, biomolecular and clinical relationships with the heart. Nat Clin Pract Cardiovasc Med. 2005;2(10):536-43.

10. Baker AR, Silva NF, Quinn DW, Harte AL, Pagano D, Bonser RS, et al. Human epicardial adipose tissue expresses a pathogenic profile of adipocytokines in patients with cardiovascular disease. Cardiovasc Diabetol. 2006;5:1.

11. Oba K, Maeda M, Maimaituxun G, Yamaguchi S, Arasaki O, Fukuda D, et al. Effect of the epicardial adipose tissue volume on the prevalence of paroxysmal and persistent atrial fibrillation. Circ J. 2018;82(7):1778-87.

12. lacobellis G, Bianco AC. Epicardial adipose tissue: emerging physiological, pathophysiological and clinical features. Trends Endocrinol Metab. 2011;22(11):450-7.

13. Cho DH, Joo HJ, Kim MN, Lim DS, Shim WJ, Park SM. Association between epicardial adipose tissue, high-sensitivity C-reactive protein and myocardial dysfunction in middle-aged men with suspected metabolic syndrome. Cardiovasc Diabetol. 2018;17:95.

14. Khaing NEE, Shyong TE, Lee J, Soekojo CY, Ng A, Van Dam RM. Epicardial and visceral adipose tissue in relation to subclinical atherosclerosis in a Chinese population. PLoS ONE. 2018;13(4):e0196328.

15. Gruzdeva O, Uchasova E, Dyleva Y, Borodkina D, Akbasheva O, BelikE, et al. Relationships between epicardial adipose tissue thickness and adipo-fibrokine indicator profiles post-myocardial infarction. Cardiovasc Diabetol. 2018;17(1):40.

16. Ng ACT, Strudwick M, van der Geest RJ, Ng ACC, Gillinder L, Goo SY, et al. Impact of epicardial adipose tissue, left ventricular myocardial fat content, and interstitial fibrosis on myocardial contractile function. Circ Cardiovasc Imaging. 2018;11(8):e007372.

17. lacobellis G, Malavazos AE, Corsi MM. Epicardial fat: from the biomolecular aspects to the clinical practice. Int J Biochem Cell Biol. 2011;43(12):1651-4

18. Groves EM, Erande AS, Le C, Salcedo J, Hoang KC, Kumar S, et al. Comparison of epicardial adipose tissue volume and coronary artery disease severity in asymptomatic adults with versus without diabetes mellitus. Am J Cardiol. 2014;114(5):686-91.

19. Song DK, Hong YS, Lee H, Oh JY, Sung YA, Kim Y. Increased epicardial adipose tissue thickness in type 2 diabetes mellitus and obesity. Diabetes Metab J. 2015;39(5):405-13.

20. lacobellis G, Diaz S, Mendez A, Goldberg R. Increased epicardial fat and plasma leptin in type 1 diabetes independently of obesity. Nutr Metab Cardiovasc Dis NMCD. 2014;24(7):725-9.

21. Cetin M, Cakici M, Polat M, Suner A, Zencir C, Ardic I. Relation of epicardial fat thickness with carotid intima-media thickness in patients with type 2 diabetes mellitus. Int J Endocrinol. 2013;2013:769175.

22. lacobellis G, Barbaro G, Gerstein HC. Relationship of epicardial fat thickness and fasting glucose. Int J Cardiol. 2008;128(3):424-6.

23. Moher D, Liberati A, Tetzlaff J, Altman DG, Group P. Preferred reporting items for systematic reviews and meta-analyses: the PRISMA statement. J Clin Epidemiol. 2009;62(10):1006-12.

24. DerSimonian R, Kacker R. Random-effects model for meta-analysis of clinical trials: an update. Contemp Clin Trials. 2007;28(2):105-14.

25. Sterne JAC, Egger M, Smith GD. Systematic reviews in health care: investigating and dealing with publication and other biases in meta-analysis. BMJ. 2001;323:101-5.

26. Duval S, Tweedie R. Trim and fill: a simple funnel-plot-based method of testing and adjusting for publication bias in meta- analysis. Biometrics. 2000;56:455-63.

27. Chen X, Wu WJ, Wang LY, Shi YJ, Shen FX, Gu XM, et al. Association between 25-hydroxyvitamin D and epicardial adipose tissue in Chinese non-obese patients with type 2 diabetes. Med Sci Monitor. 2017;23:4304.

28. Philouze C, Obert P, Nottin S, Benamor A, Barthez O, Aboukhoudir F. Dobutamine stress echocardiography unmasks early left ventricular dysfunction in asymptomatic patients with uncomplicated type 2 diabetes: a comprehensive two-dimensional speckle-tracking imaging study. J Am Soc Echocardiogr. 2018;31(5):587-97.

29. Yazici D, Ozben B, Yavuz D, Deyneli O, Aydin H, Tarcin O, et al. Epicardial adipose tissue thickness in type 1 diabetic patients. Endocrine. 2011:40(2):250-5.

30. Vasques AC, Pareja JC, Souza JR, Yamanaka A, de Oliveira Mda S, Novaes FS, et al. Epicardial and pericardial fat in type 2 diabetes: favourable effects of biliopancreatic diversion. Obes Surg. 2015;25(3):477-85.

31. Akyürek Ö, Efe D, Kaya Z. Epicardial fat thickness and its association with cardiovascular risk in patients with type 2 diabetes mellitus. Eur J Gen Med. 2015;12(2):131-5.

32. Wang Z, Zhang Y, Liu W, Su B. Evaluation of epicardial adipose tissue in patients of type 2 diabetes mellitus by echocardiography and its correlation with intimal medial thickness of carotid artery. Exp Clin Endocrinol Diabetes. 2017;125(9):598-602.

33. Seker T, Turkoglu C, Harbalioglu H, Gur M. The impact of diabetes on the association between epicardial fat thickness and extent and complexity of coronary artery disease in patients with non-ST elevation myocardial infarction. Kardiologia polska. 2017;75(11):1177-84.

34. Wang CP, Hsu HL, Hung WC, Yu TH, Chen YH, Chiu CA, et al. Increased epicardial adipose tissue (EAT) volume in type 2 diabetes mellitus and association with metabolic syndrome and severity of coronary atherosclerosis. Clin Endocrinol. 2009;70(6):876-82.

35. Keles N, Dogan B, Kalcik M, Caliskan M, Keles NN, Aksu F, et al. Is serum Klotho protective against atherosclerosis in patients with type 1 diabetes mellitus? J Diabetes Complications. 2016;30(1):126-32.

36. Akbas EM, Hamur H, Demirtas L, Bakirci EM, Ozcicek A, Ozcicek F, et al. Predictors of epicardial adipose tissue in patients with type 2 diabetes mellitus. Diabetol Metab Syndr. 2014;6:55.

37. Aslan AN, Keles T, Ayhan H, Kasapkara HA, Akcay M, Durmaz T, et al. The relationship between epicardial fat thickness and endothelial dysfunction in type i diabetes mellitus. Echocardiography (Mount Kisco, NY). 2015;32(12):1745-53.

38. Li X, Allayee $H$, Xiang AH, Trigo E, Hartiala J, Lawrence JM, et al. Variation in IGF2BP2 interacts with adiposity to alter insulin sensitivity in Mexican Americans. Obesity (Silver Spring, Md). 2009;17(4):729-36.

39. Wong CX, Sun MT, Odutayo A, Emdin CA, Mahajan R, Lau DH, et al. Associations of epicardial, abdominal, and overall adiposity with atrial fibrillation. Circ Arrhythm Electrophysiol. 2016;9(12):e004378. 
40. Tuttle $L$, Sinacore DR, Cade WT, Mueller MJ. Lower physical activity is associated with higher intermuscular adipose tissue in people with type 2 diabetes and peripheral neuropathy. Phys Ther. 2011;91(6):923-30.

41. lacobellis $G$, Barbaro $G$. The double role of epicardial adipose tissue as pro- and anti-inflammatory organ. Horm Metab Res = Hormon- und Stoffwechselforschung = Hormones et metabolisme. 2008;40(7):442-5.

42. Zhao X, Zhong J, Mo Y, Chen X, Chen Y, Yang D. Association of biochemical hyperandrogenism with type 2 diabetes and obesity in Chinese women with polycystic ovary syndrome. Int J Gynaecol Obstet. 2010;108(2):148-51.

43. Mazurek T, Zhang L, Zalewski A, Mannion JD, Diehl JT, Arafat H, et al. Human epicardial adipose tissue is a source of inflammatory mediators. Circulation. 2003;108(20):2460-6.

44. Kremen J, Dolinkova M, Krajickova J, Blaha J, Anderlova K, Lacinova Z, et al. Increased subcutaneous and epicardial adipose tissue production of proinflammatory cytokines in cardiac surgery patients: possible role in postoperative insulin resistance. J Clin Endocrinol Metab. 2006;91(11):4620-7.

45. Cheng KH, Chu CS, Lee KT, Lin TH, Hsieh CC, Chiu CC, et al. Adipocytokines and proinflammatory mediators from abdominal and epicardial adipose tissue in patients with coronary artery disease. Int J Obes (2005) 2008;32(2):268-74.

46. Fain JN, Sacks HS, Buehrer B, Bahouth SW, Garrett E, Wolf RY, et al. Identification of omentin mRNA in human epicardial adipose tissue: comparison to omentin in subcutaneous, internal mammary artery periadventitial and visceral abdominal depots. Int J Obes. 2008;32(5):810-5.

47. Gonzalez N, Moreno-Villegas Z, Gonzalez-Bris A, Egido J, Lorenzo O. Regulation of visceral and epicardial adipose tissue for preventing cardiovascular injuries associated to obesity and diabetes. Cardiovasc Diabetol. 2017;16(1):44

48. Barbarash O, Gruzdeva O, Uchasova E, Dyleva Y, Belik E, Akbasheva O, et al. The role of adipose tissue and adipokines in the manifestation of type 2 diabetes in the long-term period following myocardial infarction. Diabetol Metab Syndr. 2016:8:24.

49. Van Woerden G, Gorter TM, Westenbrink BD, Willems TP, van Veldhuisen DJ, Rienstra M. Epicardial fat in heart failure patients with mid-range and preserved ejection fraction. Eur J Heart Fail. 2018. https://doi.org/10.1002/ ejhf.1283.

50. Galletti F, D’Elia L, De Palma D, Russo O, Barba G, Siani A, et al. Hyperleptinemia is associated with hypertension, systemic inflammation and insulin resistance in overweight but not in normal weight men. Nutr Metab Cardiovasc Dis NMCD. 2012;22(3):300-6.

51. Pham MN, Kolb H, Mandrup-Poulsen T, Battelino T, Ludvigsson J, Pozzilli $P$, et al. Serum adipokines as biomarkers of beta-cell function in patients with type 1 diabetes: positive association with leptin and resistin and negative association with adiponectin. Diabetes Metab Res Rev. 2013;29(2):166-70.
52. Gronemeyer SA, Steen RG, Kauffman WM, Reddick WE, Glass JO. Fast adipose tissue (FAT) assessment by MRI. Magn Reson Imaging. 2000;18(7):815-8

53. Machann Jurgen, Thamer Claus, Schnoedt Birgit, Haap Michael, Haring Hans-Ulrich, Claussen Claus D, et al. Standardized assessment of whole body adipose tissue topography by MRI. J Magn Reson Imaging. 2005;21:455-62.

54. Jacob AN, Adams-Huet B, Raskin P. The visceral and subcutaneous fat changes in type 1 diabetes: a pilot study. Diabetes Obes Metab. 2006:8:524-30

55. Ouwens DM, Sell H, Greulich S, Eckel J. The role of epicardial and perivascular adipose tissue in the pathophysiology of cardiovascular disease. J Cell Mol Med. 2010;14(9):2223-34

56. Luna-Luna M, Medina-Urrutia A, Vargas-Alarcon G, Coss-Rovirosa F, Vargas-Barron J, Perez-Mendez O. Adipose tissue in metabolic syndrome: onset and progression of atherosclerosis. Arch Med Res. 2015;46(5):392-407.

57. Packer M. Epicardial adipose tissue may mediate deleterious effects of obesity and inflammation on the myocardium. J Am Coll Cardiol. 2018;71(20):2360-72.

58. Kang J, Kim YC, Park JJ, Kim S, Kang SH, Cho YJ, et al. Increased epicardial adipose tissue thickness is a predictor of new-onset diabetes mellitus in patients with coronary artery disease treated with high-intensity statins. Cardiovasc Diabetol. 2018;17(1):10.

59. Chun H, Suh E, Byun AR, Park HR, Shim KW. Epicardial fat thickness is associated to type 2 diabetes mellitus in Korean men: a cross-sectional study. Cardiovasc Diabetol. 2015;14:46.

60. Bouchi R, Terashima M, Sasahara Y, Asakawa M, Fukuda T, Takeuchi T, et al. Luseogliflozin reduces epicardial fat accumulation in patients with type 2 diabetes: a pilot study. Cardiovasc Diabetol. 2017;16(1):32.

61. Sato T, Aizawa Y, Yuasa S, Kishi S, Fuse K, Fujita S, et al. The effect of dapagliflozin treatment on epicardial adipose tissue volume. Cardiovasc Diabetol. 2018;17(1):6.

62. Xourgia E, Papazafiropoulou A, Melidonis A. Effects of antidiabetic drugs on epicardial fat. World J Diabetes. 2018:9(9):141-8.

63. Ji Q, Zhang J, Du Y, Zhu E, Wang Z, Que B, et al. Human epicardial adipose tissue-derived and circulating secreted frizzled-related protein 4 (SFRP4) levels are increased in patients with coronary artery disease. Cardiovasc Diabetol. 2017;16(1):133.

64. Ueda Y, Shiga Y, Idemoto Y, Tashiro K, Motozato K, Koyoshi R, et al. Association between the presence or severity of coronary artery disease and pericardial fat, paracardial fat, epicardial fat, visceral fat, and subcutaneous fat as assessed by multi-detector row computed tomography. Int Heart J. 2018;59(4):695-704
Ready to submit your research? Choose BMC and benefit from:

- fast, convenient online submission

- thorough peer review by experienced researchers in your field

- rapid publication on acceptance

- support for research data, including large and complex data types

- gold Open Access which fosters wider collaboration and increased citations

- maximum visibility for your research: over $100 \mathrm{M}$ website views per year

At BMC, research is always in progress.

Learn more biomedcentral.com/submissions 